\title{
Designing a model of factors affecting the transfer of concepts of advertising teasers in Consumer buying behavior of sports products
}

\author{
Mirza Hasan Hosseini ${ }^{1}$, Soheila Shakoori Yadegari ${ }^{2}$ \\ ${ }^{1}$ Professor, Faculty Member of Department of Business Administration of Payame Nour University \\ ${ }^{2}$ Phd Student in Business Administration of Payame Nour University, Iran
}

\begin{abstract}
Today, manufacturers of sports products, due to the variety and mass production of products in the market and competitive conditions, are forced to use advertising as one of the most effective marketing strategies. However, the realization of this important condition depends on the perceived usefulness of consumers and their intention to buy. Therefore, the present study aims to design and explain the factors affecting the transmission of advertising teaser concepts to consumers of sports products using the data approach. Therefore, by using theoretical and purposeful sampling method, the required data are obtained through in-depth and semistructured interviews with 21 senior managers and executives in the field of advertising and academic experts in the field of marketing management and sports marketing. The study has appropriate information, collected and analyzed in three stages of open, axial and selective coding in the form of 5 main categories including causal factors (factors related to the message, factors related to the media), contextual factors (factors related to Message audience and advertising-related factors), interfering factors (messaging disorders), strategies (advertising strategies in the field of branding, information advertising strategies and transfer advertising strategies) and consequences (Advertising effectiveness and sales promotion) were presented.
\end{abstract}

Keywords: Concept transfer, promotional teasers, promotional teasers, sports products. 


\section{Introduction and statement of the problem:}

The sports industry is one of the largest and fastest growing industries in the world, with several hundred billion dollars, the annual financial exchanges of this industry, so that in some countries twice the automotive industry and seven times the cinema industry in the sports industry, financial exchanges take place (Sharifian et al., 2016). The importance of sport for the economy is growing every day; So that sport has become one of the most lucrative economic fields. The production of sporting goods is now one of the most important industrial fields with various branches and its scope is becoming wider every day. Meanwhile, the growing movement of sports marketing in the world has had special effects on the development of world sports and has been able to generate huge monetary turnover and potential to attract many employees, high financial benefits, high advertising aspects, as well as benefits and benefits. Cultural, social provided two broad policies for its stakeholders. Among these, the connecting element between sports and economics is the subject of propaganda and induction of thoughts and meanings in order to develop and expand it in individuals and public opinion (Sarlab et al., 2015). Coordination of this concept is especially important in the field of economics and marketing for the sale of goods and services. Because businesses try to influence their customers and target markets through advertisements by showing the characteristics of related products and services, and turn their rational attitudes into conditional attitudes, and through this, the amount of Increase your sales and market share over competitors. Meanwhile, sports events and activities will not be able to expand and develop in the national and international community without the use of propaganda methods. The use of appropriate media and promotional methods has led to the presence of sports in the farthest corners of the world. Today, global brands of sporting goods have become a global product with the help of media advertising. Recreational sports activities are a variety of products in the field of sports for which the managers of relevant organizations are required to use advertising and inform the community through various media (Abdolmaleki et al., 2017). Advertising is a concept from the broad field of communication with an emphasis on mass communication. Mass communication means conveying information and transmitting thoughts, ideas and perceptions to many people at a time regardless of geographical location and boundaries. This makes marketers and advertisers aware of one of the key elements of advertising effectiveness, namely the advertising audience. Because it requires them to be familiar with the audience's ways of thinking, the audience's motivating factors and their living environment (Kordloo et al., 2012). This is difficult due to the fact that constantly changing factors affecting the audience and advertising is difficult. Because most of today's consumer information is lost in a short period of time. In addition, advertisers must attract complex audiences that are influenced by a number of factors. 
Therefore, they should use other sciences such as psychology, anthropology and sociology to get to know the audience better (Ghasemi et al., 2016, 34). One of the most important and influential issues on consumers' buying behavior at this stage is the effects of marketing communications, especially marketing messages that customers receive when making their purchasing decision. Marketing communications basically include messages that convey all the concepts and goals of marketing (Baladian, 2019). Therefore, in advertisements, the framework within the message should have a high content and what is stated in the advertisement should reflect the details of the product or service and not the preferences of customers (Esfidani et al., 2016). The advertising as one of the important elements of modern marketing as a central component Brayjht on beliefs, attitudes and expectations of customers and behavioral reactions that ultimately buy the product Mvrdnzrmy $\neg$ Bashd, there are (Kardlu et al., 2012). Therefore, commercial companies are looking for the "best" field for advertising their goods and services. Because in the field of advertising, several factors such as the content of advertising and factors inside and outside the organization affect the design of advertising. The content of the message includes those issues that are related to the message of the advertisement, such as image, attitude, perception, knowledge and awareness of the audience. Therefore, it can be acknowledged that the elements of advertising content are: the goals of the advertising message, key factors for customers, great ideas and the implementation framework of advertising (Moriarty et al., 2012). This includes one of the most effective "advertising" spaces available to owners, owners of goods and services. Therefore, in the present study, considering the research gap related to the importance of inducing meanings in advertising messages and the role of these inductions in consumer buying behavior, the researcher seeks to identify the factors and elements affecting the induction of meanings in advertising messages. Provide a comprehensive model for consumers and identify the effects of transmitting these concepts to them. Thus, the main question of this research is: 1) What is the pattern of conveying the concepts of advertising teasers on the buying behavior of consumers of sports products? 2) What factors affect the transmission of advertising teaser concepts to consumers of sports products?

\section{Theoretical literature of research}

in today's world, the media are able to shape the thoughts of the people of a society through careful and controlled planning, and to direct their behavior as desired, and to expand their desired perspective. In today's world, the media, with its modern and audience-friendly forms, is the largest and most effective tool for producing concepts, social proportions, and cultural messengers in society in general. Radio, television, magazines, and the Internet and modern media are indirect means of communication that have the power to direct, exercise taste, 
create mindset, and can be effective. The media and its quantitative and qualitative developments in all aspects of life and the development of communication from various angles have made them the pioneers of the recent movement. Imaging, needs assessment and persuasion, awareness, effective communication and use of new technology in the field of media (Ghasemi Nejad Lichaei et al., 2018).

The philosophy of marketing and its reason for existence is to create useful customers and create a loyal customer (Cutler, 2007). In this regard, advertising as one of the marketing tools is trying to convey the same approach and attitude to its target audience and customers. Advertising is one of the most visible marketing activities and one of the most important factors that create brand equity and play a key role in maintaining and increasing this asset. Advertising as one of the most important marketing tools can play a very important role in the company's marketing policies and strategies such as communication with customers, improving and changing the mindset of customers towards the company (Bakhtiari et al., 2015). Bartz (1957), thinking about advertising must not only pursue superficial effects, but must also seek in-depth theories. Therefore, we need to first explain the essence of the problems in advertising to explain the diverse phenomenon. Because without a strong theoretical basis, advertisements can only convey interesting visual images. Therefore, understanding some theoretical areas is very important. Chomsky (1957), in his theory of linguistic grammar, states that each sentence has two types of structure: the underlying structure that conveys the meaning of the sentence and the apparent structure that determines how words and phrases are placed. Hence the mind must make a transformation to move from one structure to another. The main purpose of grammar is to create a linguistic structure that separates all grammatical parts from non-grammatical parts of the target. Advertising concepts and slogans are also a written or oral sentence that conveys a message and concept in the underlying structure. In the apparent structure, words are mentioned, short and long, melodic, and the like. In other words, the slogan of advertising has an underlying structure and an outward structure. In the infrastructure structure, the attraction of advertisements, which is the foundation of the concept and message of advertisement, is mentioned. In the external structure, the form of the slogan and features such as the shortness and length of the slogan, the rhythm of the body or the absence of the slogan and the like are mentioned. There are several models for how ads work, and in Table 1 we will look at some of the most obvious: 
Table 1. Patterns of advertising impact on consumers

\begin{tabular}{|c|c|c|c|}
\hline Criticism & $\begin{array}{c}\text { The main } \\
\text { assumption }\end{array}$ & $\begin{array}{c}\text { Summary } \\
\text { description }\end{array}$ & theories \\
\hline $\begin{array}{l}\text { - Due to the presence of } \\
\text { noise, it is possible } \\
\text { to distort the } \\
\text { communication } \\
\text { process. } \\
\text { - It can be easily } \\
\text { interpreted in such a } \\
\text { way that the } \\
\text { meaning and } \\
\text { message are } \\
\text { considered of } \\
\text { synonymous. } \\
\text { - The risk } \\
\text { misunderstanding } \\
\text { carries interpretive } \\
\text { possibilities. }\end{array}$ & $\begin{array}{l}\text { emphasizes a } \\
\text { single message } \\
\text { that has a single, } \\
\text { simple meaning } \\
\text { and uses it as an } \\
\text { advertising } \\
\text { strategy to } \\
\text { articulate the } \\
\text { communicative } \\
\text { content they } \\
\text { want to promote } \\
\text { in advertising. }\end{array}$ & $\begin{array}{l}\text { The ad conveys a } \\
\text { message to the } \\
\text { recipients. Each } \\
\text { message has a } \\
\text { source that is the } \\
\text { sender of the } \\
\text { message. The } \\
\text { sender must } \\
\text { encrypt the } \\
\text { message in a way } \\
\text { that conveys the } \\
\text { desired meaning. } \\
\text { Encrypts the } \\
\text { message into } \\
\text { formats through } \\
\text { which } \\
\text { communication } \\
\text { can take place, } \\
\text { such as words, } \\
\text { images, gestures, } \\
\text { music, or a } \\
\text { combination of } \\
\text { all of these. The } \\
\text { recipient must } \\
\text { decrypt the } \\
\text { message to find } \\
\text { the meaning. }\end{array}$ & $\begin{array}{c}\text { Linear } \\
\text { information } \\
\text { processing } \\
\text { and } \\
\text { persuasion }\end{array}$ \\
\hline $\begin{array}{l}\text { - It is concise for its } \\
\text { fans and simplistic } \\
\text { for its opponents. } \\
\text { - Advertising-based } \\
\text { consumption is } \\
\text { considered as a } \\
\text { basically two-part } \\
\text { process that reaches } \\
\text { the individual } \\
\text { viewer through } \\
\text { communication } \\
\text { channels and is } \\
\text { consumed in social } \\
\text { isolation. } \\
\text { Only represents } \\
\text { purchases that } \\
\text { require a lot of } \\
\text { participation. }\end{array}$ & $\begin{array}{l}\text { in the linear } \\
\text { continuum, the } \\
\text { consumer moves } \\
\text { through various } \\
\text { mental states, } \\
\text { from ignorance } \\
\text { to awareness, } \\
\text { and then interest } \\
\text { arises and a } \\
\text { desire arises (for } \\
\text { the brand in } \\
\text { question). }\end{array}$ & $\begin{array}{l}\text { The consumer is } \\
\text { considered a } \\
\text { single entity that } \\
\text { resists marketing } \\
\text { communications, } \\
\text { eventually } \\
\text { leading to an } \\
\text { increasing } \\
\text { amount } \\
\text { persuasive of } \\
\text { messages of } \\
\text { delivery (ie, } \\
\text { purchase). }\end{array}$ & $\begin{array}{l}\text { Hierarchy } \\
\text { of effects }\end{array}$ \\
\hline
\end{tabular}


One of the most important and effective elements that has made the link between sports and the economy effective is the subject of advertising. Creating market and demand and maintaining and increasing market share are the goals of advertising using sports. In the meantime, the role of effective and attractive advertising that is acceptable in the world of advertising is very important. So that it creates a positive attitude among people who receive advertising (Gerdloo et al., 2015).

\section{2-1. Factors affecting the transmission of advertising concepts on consumer behavior}

Commercial advertising includes any type of advertising activity in public and urban, environmental and media spaces (written, audio and visual such as press, radio, television, etc.) with the aim of introducing and offering goods, information and services by relevant tools. It takes place on a limited or extensive level. It is clear that according to this definition, commercial advertising is a relatively new phenomenon in the history of human life, which due to its great expansion and development, has become an important thing for study and research in various fields of knowledge. The purpose of advertising is to inform the audience and persuade them to a specific action, ie the purchase of goods or services advertised, and in the form of a collection of words, images, music, etc. is sent to the recipient of the message to achieve its goals. Considering the basic tendencies in the field of the history of propaganda in various print and wave media (radio and television), it is inferred that in this field the strategy of rationality is decreasing and vice versa, sentimentality is increasing. Nowadays, its advertisements are no longer designed based on the rational mind of consumers and do not emphasize the quality and price of goods, but rather pay attention to the emotional state of consumers and their personality and lifestyle (irrational strategy) (Quchani et al. 2013).

in a general classification, the types of advertisements were divided into two categories in terms of how to convey the message to the audience: 1) Non-media advertising: Non-media advertising is a type of advertising that is not paid for by the media and mainly according to local laws on items such as prizes (discount packages) and gifts that They have a separate budget from media advertising, it focuses. 2) Media advertising: Media are the channels through which messages reach the audience; In this message transmission, the content is affected by the means of communication, and the sender of the message must send his message in the form of a text (such as a book and newspaper) or an image (such as a film or television or audio via radio). Types of media ads include: A) Print media: This media includes newspapers, magazines, book covers, printed brochures of organizations, hand-to-hand street advertising and the like. B) Audio media: includes items such as radios, advertising loudspeakers on the streets, shopping malls, exhibitions and other similar items. C) Audio-audio and electronic media: 
Such media are classified according to the type of technology used in the form of film, telephone, television and other new means of communication such as the Internet and social networks (Ghasemi et al., 2019). Moriarty et al. (2012), several factors such as the content of advertising and internal and external factors affect the design of advertising. The content of the message includes those issues that are related to the message of the ad - such as image, attitude, perception, knowledge and awareness of the audience. Therefore, in determining and designing the message strategy, marketers try to create messages that, while strengthening the position and position of the brand, also raise its similarities and differences. This is because some messages are directly related to the product or service, such as messages about quality, economy, or brand value, while others are related to abstract and external factors, such as related messages. By being creative, famous or traditional brand (Trung et al., 2016).

In the field of advertising, several factors such as the content of advertising and internal and external factors affect the design of advertising. The content of the message includes those issues that are related to the message of the advertisement, such as image, attitude, perception, knowledge and awareness of the audience. Thus, it can be acknowledged that the elements of advertising content are: the goals of the advertising message, key factors for customers, great ideas and the implementation framework of advertising (Moriarty et al., 2012). Dance et al. (2015), the dimensions affecting the transmission of advertising message in emotional advertising are: 1) Introducing and increasing the audience's awareness of the brand; 2) Negative emotional dimension (induction of sad feeling); 3) Positive emotional dimension (inducing a sense of joy and cheerfulness). John Wickens (2017), Factors affecting the power of conveying concepts in advertising are: 1) core value; 2) ability to attract attention; 3) The ability to touch (emotions such as worry, fear, love, nostalgia, etc.). Mayer et al. (2018), the factors affecting the content of the ad to the audience are: 1) the information of the ad;2) the acceptability and agreement of the advertisement; 3 ) psychological and motivational stimuli in the presented text; 4) brand familiarity; 5) symbolic connection of the pattern; 6) imitate; 7) repeated claims; 8) Commitment to what it offers.

\section{2-2. Empirical background of the research}

Lee Pen (2017), in a case study on billboard advertising in Hong Kong, examines the multimedia and texture in the translation of this type of advertising. Boroujerdi Alavi et al. (2017), in a study entitled "Semiotics of Public Service Advertisements on Iranian Television Advertisements Related to the Support of Iranian Goods", the producers of these advertisements, to encourage people to support national production and break the myth. Good quality "foreign goods And to prevent consumerism, by showing the purchase of foreign products by 
Iranians, which leads to the closure of factories and unemployment of workers, they try to provoke the emotions and feelings of the audience. Elements of storytelling, Chinese introduction, personalities of the people themselves, hope for the next generation, etc. are also used in these ads. Sadat Moghaddari (2016), in a study entitled "Analysis of the Commercial Billboard Discourse from the Perspective of Multimedia Analysis", the billboards of the present study indicate the demand component and include the presentation component. It can mean that advertising in Iran offers goods independently of demand and buyers, and therefore will not have much demand to attract.

esfidani et al. (2016), in a study found that television advertising strategies are: 1) uniqueness (creativity and innovation in advertising); 2) information advertising (product or service introduction); 3) Transitional advertising (persuading the audience to buy) Kordloo et al. (2015), in a study entitled "The relationship between causal beliefs, attitudes toward advertising through sports and publicity", people's beliefs about advertising through sports can affect people's attitudes toward publicity. Also, the belief that economics is more than other people's beliefs has the power to explain people's attitudes toward advertising through sports.

\section{Research method}

This research follows the data research strategy of the foundation, therefore the purpose of this study is to explore and understand more about the research model and variables. Grounded theory is an inductive research method with a completely "qualitative" approach and an "exploratory" research method. This feature enables the researcher to personally formulate a new theory instead of using predefined theories in cases where it is not possible to formulate a hypothesis. The data design research theory of the foundation intended for this research is the systematic design of Strauss and Corbin (1998). Data collection tools in this research are library studies including the use of books, articles and the World Wide Web to gather information on the theoretical foundations of research related to the research topic, as well as field methods including interviews. And observation to provide information for qualitative analysis of data. Based on this, in-depth and semi-structured interview techniques were used to collect data, and since the interview method was in-depth and semi-structured, in conducting interviews, attempts were made to extract and extract existing facts by asking questions about research-related events. The statistical population of this study is 21 key learners, senior managers and executives in the field of advertising and academic experts and elites in the field of marketing management and sports marketing who have relevant information in the field of research. In this research, theoretical sampling methods and snowballs have been used. Data analysis based on the systematic scheme of Strauss and Corbin (1998), during the 
three-step open coding process (compilation of information classes); Axial coding (linking these classes) and selective coding (presenting a report linking these classes) have been done. Also, in order to maintain the validity of the research, during the process of data analysis and collection, which is done simultaneously in a foundation data research, the opinions of academic elites in the field of business management and marketing to confirm the accuracy of coding and classification Obtained.

\section{Qualitative analysis of research data}

After compiling the research questions, the required data are collected and coded. The process of data analysis in theory development theory is based on the stage of open coding (creation of concepts and categories); Axial coding $\neg$ (identification of the main category, causal conditions, interventionist conditions, contextual conditions, strategies and consequences) and selective coding (theory creation) (Ali Ahmadi, 2018).

\section{4-1. Open transition code}

Accordingly, in this part of the research, after the experts and scholars in the field were identified and interviewed using the snowball method, using the mechanism of data theory theory; The interviews were reviewed. In the first study cycle, the first 22 interviews were selected based on the initial line-by-line review, from each interview, sentences that directly or indirectly referred to the factors affecting the transmission of advertising teasers in the buying behavior of consumers of its sports products were selected and extracted. Their concepts were extracted. In this stage, a total of 34 initial codes were identified in terms of repetitions from the text of the interviews (open coding).

\section{4-2. Axial coding}

At this stage, the researcher puts one of the categories at the center of the process under study and exploration (the main phenomenon) and then relates the other categories to it; These categories include causal conditions (causes of the main phenomenon), strategies (actions or reciprocal actions performed to control, manage, deal with, and respond to the main phenomenon), context or context (specific contextual conditions). Effective in strategies), intervening conditions (general bedrock conditions affecting strategies) and consequences (results of implementing strategies). 
Table 2. Categories and concepts related to causal conditions

\begin{tabular}{|c|c|c|}
\hline $\begin{array}{c}\text { Concepts (open source) } \\
\text { Validity and validity of the message }\end{array}$ & $\begin{array}{c}\text { Categories } \\
\text { Factors related to } \\
\text { the message } \\
\text { The fit of the ad to the topic }\end{array}$ & $\begin{array}{c}\text { Causal with the media } \\
\text { conditions }\end{array}$ \\
\hline The physical and visual charm of the message \\
Message style
\end{tabular}

Table 4. Categories and concepts related to intervening conditions

\begin{tabular}{|c|c|c|}
\hline Concepts (open source) & $\begin{array}{c}\text { Categories } \\
\text { Disruptions in } \\
\text { message } \\
\text { transmission }\end{array}$ & $\begin{array}{c}\text { Dimensions } \\
\text { Interfering } \\
\text { conditions }\end{array}$ \\
\hline Fault in message transmission tool & \\
\hline Transmitting the message at the wrong time & \\
\hline
\end{tabular}

Table 5. Categories and concepts related to contextual conditions

\begin{tabular}{|c|c|c|}
\hline $\begin{array}{c}\text { Concepts (open source) } \\
\text { Audience cultural characteristics }\end{array}$ & $\begin{array}{c}\text { Categories } \\
\text { Factors related } \\
\text { to the message } \\
\text { recipient }\end{array}$ & $\begin{array}{c}\text { Dimensions } \\
\text { Background } \\
\text { conditions }\end{array}$ \\
\hline $\begin{array}{c}\text { Individual characteristics of the audience } \\
\text { Psychological characteristics of the audience }\end{array}$ & $\begin{array}{c}\text { Factors related } \\
\text { to advertising }\end{array}$ \\
\hline The quality of the tiles & \\
\hline Advertising techniques & \\
\hline Ad duration, ad duration and timing & \\
\hline Simplicity and clarity of concepts & \\
\hline
\end{tabular}

Table 6. Categories and concepts related to strategies

\begin{tabular}{|c|c|c|}
\hline Concepts (open source) & Categories & Dimensions \\
\hline Scenario design tailored to the desired product & \multirow{3}{*}{$\begin{array}{c}\text { Advertising } \\
\text { strategies in } \\
\text { the field of } \\
\text { branding }\end{array}$} & \multirow[t]{10}{*}{ Strategies } \\
\hline $\begin{array}{l}\text { Proportion of message structure and content to brand } \\
\text { position }\end{array}$ & & \\
\hline Transparency in message transmission & & \\
\hline increasing the audience's awareness of the product & \multirow{3}{*}{$\begin{array}{c}\text { Information } \\
\text { advertising } \\
\text { strategies }\end{array}$} & \\
\hline Communication pattern (one-way / two-way) & & \\
\hline $\begin{array}{l}\text { Use the concept of comparison to influence the } \\
\text { audience }\end{array}$ & & \\
\hline Minimal and message-related atmosphere & \multirow{4}{*}{$\begin{array}{c}\text { Transitional } \\
\text { advertising } \\
\text { strategies }\end{array}$} & \\
\hline Motivate to buy products & & \\
\hline $\begin{array}{c}\text { Paying attention to the audience's insight in } \\
\text { designing and making ads }\end{array}$ & & \\
\hline $\begin{array}{c}\text { Creating a mental conflict in the audience towards } \\
\text { the ad }\end{array}$ & & \\
\hline
\end{tabular}


Table 7. Categories and concepts related to consequences

\begin{tabular}{|c|c|c|}
\hline Concepts (open source) & Categories & Dimensions \\
\hline Understand the value of the advertiser brand & $\begin{array}{c}\text { Advertising } \\
\text { effectiveness }\end{array}$ & consequences \\
\hline $\begin{array}{c}\text { Changes in their beliefs, values or attitudes } \\
\text { Informing and educating consumers }\end{array}$ & \\
\hline Convincing the audience & Sales progress & \\
\hline Return on investment & \\
\hline Optimal use of production factors & \\
\hline
\end{tabular}

4-3. Selective coding and the emergence of theory

In the last stage of coding, ie selective coding, the central category is selected from among the categories and theories from the heart of the research are presented around it. Selective coding based on the results of open coding and axial coding is the main stage of theorizing (Strauss and Corbin, 2012).

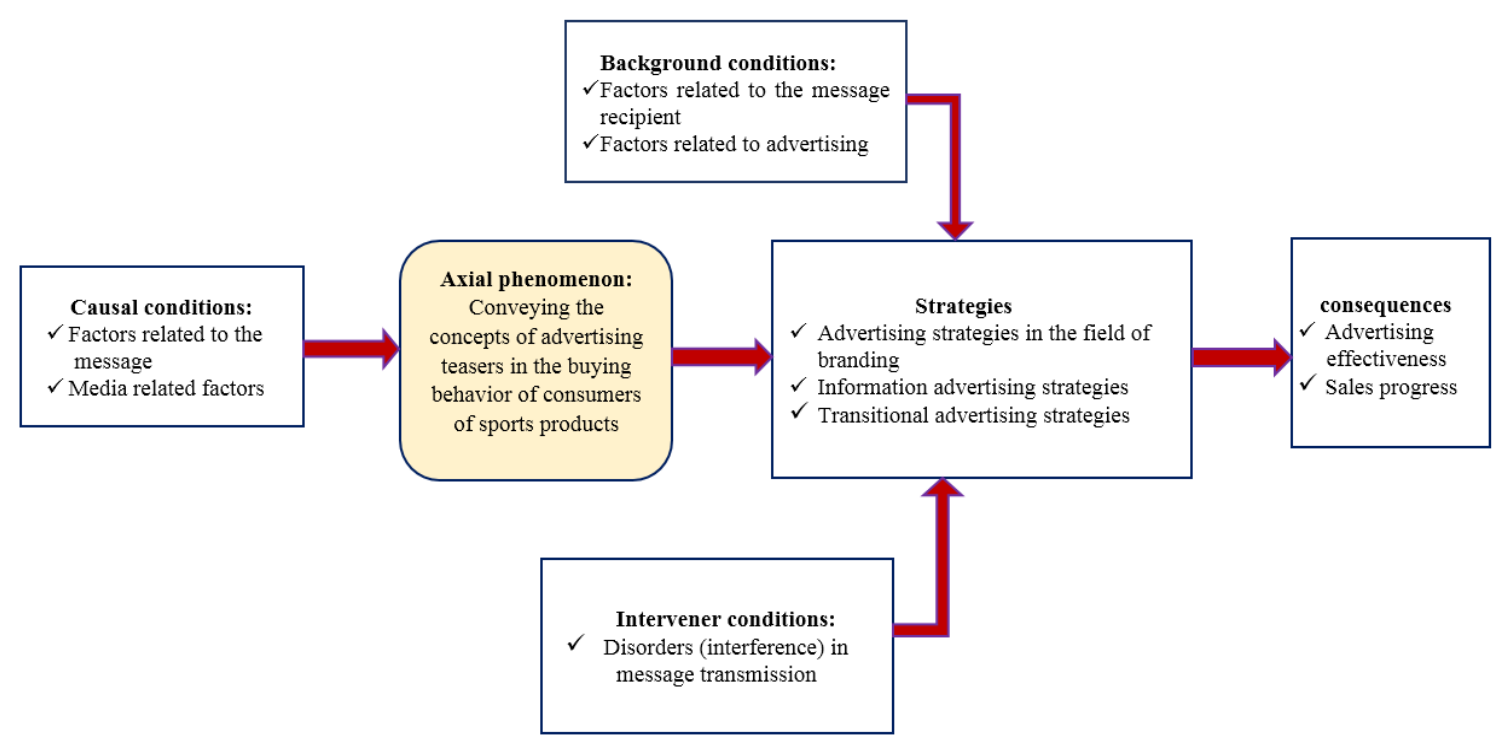

\section{Discussion and conclusion}

Advertising products in the field of economics, especially in the field of marketing and sales, is a common way to introduce product specifications to customers in such a way that in the light of these advertisements, customers get the appropriate information about the product and its functions. Accordingly, one of the most important and at the same time the most effective connecting elements of economics and sports is the issue of propaganda, which means the method of inducing thinking to expand and develop in the minds of individuals and the public. Therefore, a marketing plan will be successful when it is able to convey the concepts and meanings of the manufacturer to the consumer's relative and, in addition to informing him about the sport product, persuade him to buy it. . In the 
present study, due to the existing research gap in the field of transmitting advertising concepts to consumers, especially in the field of research products, the exploratory research approach and data theory method of the Strauss and Corbin paradigm model foundation were used. Thus, after conducting in-depth interviews with experts and conducting extensive theoretical studies, the theoretical model of research based on open, axial and selective coding has been developed through a reciprocal process from within the data and the signs and concepts identified in the format The categories were categorized and finally a qualitative model was obtained. The model obtained from this research is presented as follows:

Causal conditions: Based on the results of this study, two categories of factors related to the message and factors related to the media were identified as causal conditions for conveying the concepts of advertising teasers in the buying behavior of consumers of sports products.

Underlying conditions: These conditions include a set of factors that lead to the adoption of strategies that

Axial phenomenon: Conveying the concepts of advertising teasers in the buying behavior of consumers of sports products

They are effective and are referred to as underlying factors. In this research, this set of conditions have been identified and named as human capital.

Interfering Conditions: In this study, those factors that indirectly affect the transmission of the concepts of advertising teasers in the buying behavior of consumers of sports products were identified and classified in the form of intervening conditions. Based on this, the category of disorders (parasites) in message transmission were identified as interfering conditions.

Strategies: are actions or interactions that arise from the central phenomenon and their purpose is to provide solutions to deal with the central phenomenon. In this study, the strategies for realizing the pattern of conveying the concepts of advertising teasers in the buying behavior of consumers of sports products under the influence of two sets of intervening factors and prevailing contexts are advertising strategies in the field of branding, information advertising strategies and strategy. Transitional advertising.

\section{references}

Abdul Maleki, Hussein Mirzadeh, Zahra Sadat. Ali Doost Ghaghrokhi (2015). Ranking of Factors Affecting Consumer Behavior of Sports Products Using AHP. Sports Management, No. 3, pp. 471-488.

Bakhtiari 9 Kaveh; Reza Karimizadeh; Sara Dehgerdi and Sasan Teymouri, 2015, The concept of advertising and its role in marketing, the first scientific conference on management and planning, education and standardization of Iran, Tehran, 
Association for the Development and Promotion of Basic Sciences and Technologies.

Baladian, Seyed Mostafa, Asarehnejad Dezfuli, Sina, Bagheri, Mehdi and Homayoun, Mohammad Hadi (2019). "Extraction and leveling of effective components on increasing the effectiveness of Internet advertising". Journal of Media Studies, Year 13, Issue 4, Sequential 43. Pages 31-48.

Esfidani, Mohammad Rahim; Kimasi, Massoud and Ahmadi, Salah (2015). A framework for determining advertising strategies in banking. Journal of Marketing Management, Volume 3, Number 3, pp. 142-118.

Ghasemi, Hamid; Lashkar, Sara and Rasekh, Nazanin (1397). Advertising and sports. Andisheh Ara Publications, sixth edition.

Moriarty, S., Mitchell, N., \& Wells, W. (2012). Advertising \& IMC: Principle and Practice (9th ed). Harlow, England: Pearson Education Limited.

Qasem Nejad Lichaei, Seyedeh Sedigheh; Reza Sufi, Morteza and Mohammadi, Nasrallah (1397). Thesis entitled "Study of the role of media advertising in the development of sports tourism (Case study: Gilan province)". Payam Noor university.

Quchani, Farrokh. Hashemnia, Shahram and Iqbal, Roya (2013). Investigating the effect of various types of media advertising as one of the marketing strategies on the behavior of car buyers, Journal of Marketing Management, No. 20, pp. 103121.

Kurdloo, Hussein; Alireza Elahi and Khodayari, Abbas (2014). The relationship between causal beliefs, attitudes toward advertising through sport, and publicity. Sports Management Studies, No. 30, pp. 224-203.

Kordlu H. Belief`s and Attitude of Irannian Football Premier Leaque`s Spectators toward Advertising through Sport. [ M. A]. Kharazmi university; 2012.

Sarlab, Roghayeh. Abdavi, Fatemeh (2014). Marketing and the role of advertising in the sports industry. Journal of Management and Organizational Behavior in Sports, Year 3, Issue 1, pp. 37-47.

Sharifian, Ismail. Yousefi Zarandi, Mohammad Hussein Ghahremani Tabrizi, Kourosh (2015). Intra-sectoral barriers to the sports industry in competition with foreign sporting goods, Applied Research in Sports Management, Fifth Year, No. 1, pp. 73-82. 